\title{
Jardins botânicos e turismo de jardins: pesquisa de audiência em Porto Alegre e Caxias do Sul, RS ${ }^{1}$
}

Botanical gardens and gardens tourism: audience research in Porto Alegre and Caxias do Sul, RS

Jardines botánicos y garden tourism: pesquisa de audiencia en Porto Alegre y Caxias do Sul, RS

http://dx.doi.org/10.18472/cvt.18n1.2018.1314

Susana Gastal « susanagastal@gmail.com > Universidade de Caxias do Sul (UCS), Caxias do Sul, RS, Brasil.

Viviane Rocha 〈duda@dudarocha.com.br > Universidade de Caxias do Sul (UCS), Caxias do Sul, RS, Brasil.

Antônio Carlos Castrogiovanni < castroge@ig.com.br > Universidade Federal do Rio Grande do Sul (UFRGS), Porto Alegre, RS, Brasil.

1 Projeto de pesquisa com apoio do CNPq.

CRONOLOGIA DO PROCESSO EDITORIAL

Recebimento do artigo: 18-mar-2016

Aceite: 15 -nov-2017

FORMATO PARA CITAÇÃO DESTE ARTIGO

GASTAL, S.; ROCHA, V.; CASTROGIOVANNI, A. C. Jardins botânicos e turismo de jardins: pesquisa de audiência em Porto Alegre e Caxias do Sul, RS. Caderno Virtual de Turismo. Rio de Janeiro, v. 18, n. 1, p. 170-186, abr. 2018.
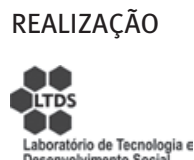
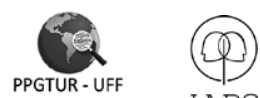

IABS
APOIO INSTITUCIONAL

COPPE
EDIÇÃO

IPITRE

$=$
PATROCÍNIO

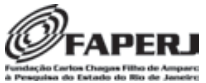




\section{RESUMO}

Os jardins botânicos receberam 200 milhões de visitantes em 2010, alimentando um turismo de nicho associado ao garden tourism. Para melhor conhecer o segmento, o artigo apresenta resultados de pesquisas de nível exploratório sobre o perfil do visitante, realizadas nos Jardins Botânicos de Porto Alegre e Caxias do Sul/RS, comparando-os. Nelas utilizou-se o mesmo questionário com perguntas abertas e fechadas, com amostra aleatória e por exaustão. Para discussão teórica sobre turismo de jardins, seguem-se Silva e Carvalho (2013), De Angelis e De Angelis Neto (1998), e Silva (2013). Para sustentação metodológica tratada como "pesquisa de audiência", segue-se o Botanic Gardens Conservation International, que indica tal procedimento, como aprofundado por Moussouri (2013). As pesquisas detectaram que o frequentador dos locais possui educação superior e busca tais áreas para lazer qualificado. Em Porto Alegre há maior conscientização da função patrimonial e científica dos jardins botânicos, já em Caxias do Sul, os frequentadores desconhecem essas especificidades. ${ }^{2}$

Palavras-chave: Turismo de jardins. Jardim botânico. Pesquisa de audiência. Porto Alegre-RS. Caxias do Sul-RS, Brasil.

\section{ABSTRACT}

Botanical gardens received about 200 million visitors in 2010, feeding a tourism niche associated with garden tourism. To better understand this segment, this article presents the results of an exploratory research, carried out in Porto Alegre and Caxias do Sul Botanical Gardens, comparing them. On all occasions the same questionnaire was used, with open and closed questions, with random sample and exhaustion. The theoretical discussion on garden tourism follows Silva and Carvalho (2013), De Angelis and De Angelis Neto (1998), Silva (2013), Brum and Santiago (2011), and others, and Botanic Gardens Conservation International itself for methodological support of 'research audience', as presented by Moussouri (2013). The results conclude that the average visitor has good education, economic and cultural level, and they search these areas for qualified leisure. In Porto Alegre there is awareness about heritage and scientific function of the gardens, and very critical terms about the structure, service, signaling and security offered by the park; in Caxias do Sul goers are unaware of these differentials.

Keywords: Garden tourism. Botanic garden. Audience research. Porto Alegre-RS. Caxias do Sul-RS, Brazil.

\section{RESUMEN}

Los jardines botánicos recibieron cerca de 200 millones de visitantes en 2010, impulsando un turismo de nicho asociado al garden tourism. Para mejor comprender este segmento, este artículo presenta resultados de investigación a nivel exploratorio sobre o perfil del visitante, realizada en los Botánicos de Porto Alegre y Caxias do Sul, RS, comparándolas. Ellos utilizan el mismo cuestionario con preguntas abiertas y cerradas, con una muestra aleatoria y agotamiento. La discusión teórica sobre turismo de jardines sigue a Silva y Carvalho (2013), De Angelis y De Angelis Neto (1998), Silva (2013), Brum y Santiago (2011), y el propio Botanic Gardens Conservation International para sustentación metodológica de la investigación, tal como presentado por Moussouri (2013). Las investigaciones han encontrado que el frecuentador de los dos sitios tiene un buen nivel educativo, económico y cultural, que busca en estas zonas ocio cualificado. Mientras que en Porto Alegre existe mayor conciencia de la herencia cultural y la función científica de los botánicos, y en estos términos son críticos en su evaluación, en Caxias do Sul los visitantes no son conscientes de estas diferencias.

Palavras clave: Turismo de jardines. Jardines botânicos. Pesquisa de audiencia. Porto Alegre-RS. Caxias do Sul-RS, Brasil.

\footnotetext{
2 A versão inicial deste artigo foi apresentada no IX Congreso de Investigadores en Turismo e VIII Foro Nacional de Turismo, em 2015 , ambos no Chile, sem incluir dados e análise da pesquisa no Jardim Botânico de Caxias do Sul. A presente versão apresenta-se ampliada nesses termos, mas também na inclusão da reflexão sobre a relação turismo-cotidiano.
} 


\section{INTRODUÇÃO}

O atual cenário sociocultural, considerando a pós-modernidade - momento em que a sociedade está culturalizada e a natureza se foi para sempre, no dizer de Jameson (2001, p. 161) -, encaminha tendências que marcariam os neocotidianos. Apresentar a sociedade como culturalizada, significa entender que todos os espaços do planeta estariam, na atualidade, submetidos à ação humana, levando à apropriação da natureza na forma de jardins botânicos e ou jardins históricos, por exemplo, como apresentado adiante. Entende-se, no âmbito deste artigo e da pesquisa, que na atualidade passam a conviver, no mesmo espaço social, hábitos diários associados ainda a uma sensibilidade tradicional ou mesmo moderna, em termos de modos de ser e estar no mundo, e outros já condicionados pela lógica da globalização, os quais tratamos como neocotidianos. Daí considerar-se que, mesmo no interior dos grupos sociais, as rotinas diárias podem ser múltiplas, permitindo falar não em cotidiano, mas em cotidianos, e defender que, no mesmo caso, algumas sensibilidades em termos de rotinas diárias estariam mais submetidas aos reflexos do mundo globalizado - levando ao tratamento como neos, e outras ainda vivenciadas sob lógicas mais tradicionais.

Entre as marcas do mundo sob a globalização se destacam o protagonismo das cidades e a urbanização crescente do planeta, tornando escassos os verdes citadinos ou mesmo a possibilidade de desfrute do lazer em espaços abertos, o que valoriza os jardins botânicos e outras áreas verdes, como os jardins históricos. Outra marca contemporânea diz respeito à crescente movimentação das pessoas dentro das cidades, facilitada pelos avanços tecnológicos e por políticas públicas de qualificação da mobilidade, mas também repercutindo nos deslocamentos inter-regionais e internacionais, com consequências diretas sobre o turismo, ou seja, cada vez mais, há um maior número de viajantes, gerando não apenas o dito turismo de massa, como a especialização das viagens. (MASCARENHAS, 2014; GALLI, 2015).

Tratam-se, agora, de viajantes que percorrem longas distâncias, mas que também realizam rápidos deslocamentos, pois os mobiliza menos a busca por novos lugares e mais o desfrute de novas experiências (MOLINA, 2003), pautadas por estranhamentos. Nesses termos, seria esta categoria - o estranhamento - e não a distância percorrida, o que indicaria um sujeito como turista. (GASTAL; MOESCH, 2007; CAMPOS, 2012). Considera-se, por fim, que o turismo também demarca a cultura do cotidiano, ou seja, o dia a dia de muitas camadas da sociedade, pois seria parte "[...] do modo como nós percebemos o mundo a nossa volta, independente de quem sejamos ou do que façamos. É uma maneira de ver e sentir o mundo" (FRANKLIN; CRANG, 2001, p. 9), que se embasa cada vez mais em processos de mobilidade e de fluxos de longo ou pequeno alcance, mas em ambos os casos significando contatos com expressões culturais diversificadas.

Feitas as considerações iniciais, o presente artigo objetiva apresentar resultados de pesquisa de nível exploratório, realizada em 2012, que buscou analisar perfil dos frequentadores [audiência], assim como suas expectativas em relação ao Jardim Botânico de Porto Alegre-RS, comparando-os com dados recolhidos no mesmo local em 2006; e em 2015 no Jardim Botânico de Caxias do Sul-RS, ambas as cidades situadas no extremo Sul do Brasil. Nas três oportunidades, buscou-se levantar dados sobre o perfil e expectativas em relação às duas áreas, utilizando-se para tal o mesmo questionário com perguntas abertas e fechadas, com amostra aleatória e por exaustão na sua aplicação. Trata-se de um procedimento em que os entrevistados são abordados aleatoriamente, e aplica-se o número de entrevistas possíveis em períodos previamente determinados de tempo; no presente caso foram ouvidos 41 visitantes em seis dias do mês de abril de 2012 e 61 visitantes em nove dias do mês de maio de 2006; em 2015, ao longo de seis dias, foram entrevistadas 
89 pessoas. Foram considerados períodos de três horas em cada um dos dias de aplicação, e o número de entrevistados variando conforme a presença (bastante variável) de frequentadores, em cada um dos dias e locais.

De acordo com a Rede Brasileira de Jardins Botânicos, existem quatro jardins botânicos registrados no Rio Grande do Sul, respectivamente nas cidades de Porto Alegre, Caxias do Sul, Santa Maria e Lajeado. A escolha dos jardins botânicos de Porto Alegre e de Caxias do Sul, para o presente estudo, justifica-se no âmbito de projeto de pesquisa conjunto, pela Universidade de Caxias do Sul e pela Universidade Federal do Rio Grande do Sul, com apoio do CNPq, que até o momento inclui três dissertações concluídas, além de bolsas de iniciação científica, em ambas as instituições. Assim, priorizaram-se, no primeiro momento, os jardins botânicos nas cidades-sede das duas Universidades partícipes.

\section{TURISMO DE JARDINS E TURISMO DE NICHO}

As características únicas de cada jardim botânico, sua carga simbólica e histórica servem como justificativa para que os pesquisadores do Turismo conduzam novos olhares para a consolidação desses espaços como atrativos turísticos. Os jardins estão entre os atrativos turísticos mais destacados, sendo exemplo o Central Park (Nova York, EUA), o Tivoli (Dinamarca), o Giverny (França), que foi o refúgio do pintor Monet, assim como os jardins Zen (Japão) e o Keukenhof (Holanda), "que goza do estatuto de maior jardim de flores do mundo [...] que abre apenas dois meses por ano e recebe 800 mil visitantes por temporada." (SILVA; CARVALHO, 2013, p. 635). Há, inclusive, jardins classificados pela Unesco como Patrimônio Mundial, caso do Royal Exhibition Building and Carlton Gardens (Austrália), do Palace and Gardens of Schönbrunn (Áustria), do Classical Gardens of Suzhou (China) e do Kew Gardens (GrãBretanha) (GASTAL; FAGUNDES, 2015; PALMA; GASTAL, 2016). Os mesmos autores apresentam, ainda, números de visitação registrados nas primeiras décadas do século XXI (Quadro 1, conforme sistematização de GASTAL; FAGUNDES, 2015), para justificar a atratividade que os jardins podem alcançar. Embora relatem números de anos diferentes, Silva e Carvalho defendem que esse universo de frequentadores superaria os da Disneylândia e do Disneyworld, juntos.

Quadro 1 - Número de visitantes em jardins

\begin{tabular}{|l|l|l|}
\hline \multicolumn{1}{|c|}{ PAíS } & \multicolumn{1}{c|}{ JARDIM } & VISITANTES \\
\hline França & Giverny & $500 \mathrm{mil} / \mathrm{ano}$ \\
\hline França & Versailles & $8 \mathrm{milhões} / \mathrm{ano}$ \\
\hline Holanda & Keukenhof & $800 \mathrm{mil} / \mathrm{temporada}$ \\
\hline Grã-Bretanha & 400 jardins abertos & $16 \mathrm{milhões} /$ ano \\
\hline Irlanda & 7 jardins & $876 \mathrm{mil} / \mathrm{ano}$ \\
\hline Nova Zelândia & Christchurch & $1.2 \mathrm{milhão} / \mathrm{ano}$ \\
\hline
\end{tabular}

Fonte: Gastal e Da Silva (2015), a partir de dados de Silva e Carvalho (2013)

A busca pelos jardins, além do até aqui apresentado, também se daria porque, na economia pósfordista, o turismo deixa de se dar como excepcionalidade e passa a integrar a vida cotidiana. Esse "turismo da vida cotidiana pode ser visto, em parte, como a expansão da flânerie" (FRANKLIN; CRAG, 2001, p. 4), em que todos, independentemente de estarem em sua própria cidade ou fora dela, vivem em um 
mundo "reconfigurado como interessante, divertido e atrativo [...]. A maioria das pessoas agora é parte de um mercado, inicialmente focado apenas em visitantes externos." (FRANKLIN; CRAG, 2001, p. 9). Moesch e Gastal (2007), em termos semelhantes, colocam a categoria turista cidadão, para indicar aquele que percorre a cidade de residência, impactado pelo mesmo estranhamento a que é submetido o turista tradicional.

Os arrazoados até aqui apresentados, portanto, buscam demonstrar que o turismo contemporâneo insere-se também sobre os cotidianos, além de marcar-se pela demanda por produtos e experiências de qualidade. Permite, ainda, pensar em cidades de porte médio com atratividade turística, mesmo que não apresentem os produtos de "sol e mar", montanha ou patrimônio cultural excepcional, os quais, por muitas décadas, foram os principais indutores do turismo mundial. Tal especialização oportuniza o que vem sendo tratado como turismo de nicho, a demandar espaços que possam ser usufruídos por visitantes de forma qualificada, em viagens, ou mesmo em deslocamentos em seu próprio local de moradia. Destacamse, assim, em simultaneidade, a emergência de turismos de nicho e a reconfiguração da figura do turista, agora não mais e apenas como aquele que percorre fronteiras regionais e internacionais, mas em uma tipologia que pode envolver experiências diferenciadas mesmo nos cotidianos, como cenários a embasar o que segue.

No cenário contemporâneo, marcado por pós-turismos - e aqui também no plural, pois sob o ponto de vista da especialização das segmentações, teríamos muitas formas diferentes de exercício das viagens, levando a turismos, no plural -, os jardins botânicos aparecem em situação de destaque, como registra o Botanic Gardens Conservation International (BGCI, 2010), que estima em 200 milhões o número anual de visitantes nesses parques, o que poderia incluir tanto o morador do seu entorno como visitantes vindos de outras geografias, o especialista em botânica e o aficionado em jardinagem, ou o simples curioso. Tal demanda leva a literatura a discorrer sobre o que tem sido denominado como turismo de jardins [garden tourism ou garden visiting] (DE ANGELIS; DE ANGELIS NETO, 1998; SILVA, 2013; BRUM; SANTIAGO, 2011; PALMA; GASTAL, 2016). O turismo de jardim incluir-se-ia como uma tendência importante do turismo de nicho, compreendendo-se por tal que "nicho mais não é do que um pequeno mercado constituído por um cliente individual ou um pequeno grupo de clientes com as mesmas características ou necessidades." (SILVA; CARVALHO, 2013, p. 633).

Apesar da grandeza dos números envolvidos, tratar-se-ia de um segmento ainda embrionário, mas em crescimento desde a década de 1990, especialmente na Grã-Bretanha e em Portugal, neste último em muito devido à iniciativa portuguesa de realizar levantamento dos jardins históricos do país para avaliar seu potencial turístico. Mas ainda, o cenário positivo não significaria que os jardins botânicos, a exemplo dos museus e de muitos jardins históricos reconhecidos inclusive pela Unesco (GASTAL; ROCHA, 2016) como tal, não tenham preocupações com sua manutenção financeira e maior inserção na comunidade, levando a ações em prol da fidelização dos frequentadores e da ampliação desse público em termos de número e diversificação. O BGCI utiliza a expressão "desenvolvimento de públicos" [audience development], cujos termos equivalentes seriam ampliação de visitantes [visitors], usuários [users] ou mesmo comunidades [communities]. (MOUSSOURI, 2013). Para alcançar esses objetivos, o mesmo BGCI recomenda a realização de pesquisas [audience research], ou seja, investigações que priorizem o público, sua opinião e sentimentos, na linha proposta pelos Estudos Culturais, quando propõe ouvir a audiência dos meios de comunicação. 
As pesquisas de audiência são um meio importante para conhecer como as pessoas desejam usufruir e participar, ou para produzir conteúdos com diferentes finalidades, fáceis de serem assimilados, como os processos de interpretação patrimonial e outras ações educativas que contribuam para maior consciência em relação aos jardins botânicos e aos trabalhos ali realizados; mas também de forma mais ampla, criando uma rede de apoio aos professores tanto do ensino formal como do informal. (MOUSSOURI, 2013; WHITE, 1998; VAN VALKENHOEF, 2013; WANG; HE, 2013; WILLISON, 2013).

\section{OS JARDINS BOTÂNICOS}

A presença dos jardins botânicos data do século XV, quando as embarcações envolvidas nas grandes navegações traziam, no seu retorno à Europa, espécies vegetais dos novos mundos, a seguir depositadas em áreas fechadas que garantissem a sua sobrevivência e, se possível, reprodução. Com o tempo, a função dessas áreas foi se ampliando, sendo que hoje elas têm como objetivos primordiais as pesquisas em biotecnologia, manutenção da biodiversidade, preservação do ambiente natural do planeta e interrupção da perda de espécies nativas. Além de suas próprias dependências, não raro os jardins botânicos se utilizam da mídia e do turismo para cumprir suas funções, no que se refere à conscientização preservacionista. (ROCHA; CAVALHEIRO, 2001). A mídia participa do processo tanto por seus canais tradicionais rádio, televisão, jornal - como pelas ferramentas do mundo on-line. O turismo, por sua vez, já acumula considerável experiência ao mostrar que os fluxos, a exemplo dos fixos no território, criam (e demandam) novas possibilidades de subjetivação dos sujeitos. O turismo tem ensinado a "olhar", envolvendo nessa ação não apenas a dimensão visual, mas também e pelo menos, os demais sentidos. (URRY, 1996; FRANKLIN; CRAG, 2001).

Historicamente, os jardins botânicos construíram uma longa associação com a pesquisa, as primeiras sendo auxiliares do ensino nas escolas de Medicina, "com aulas de botânica voltadas para os boticários e cirurgiões”. (CAMARGO, 2007, p. 250). Hoje, eles são valorizados em muitos países, como a Nova Zelândia, com seus 14 parques nacionais ${ }^{3}$, e a África do Sul, onde há dez jardins botânicos ${ }^{4}$, que receberiam 1,5 milhão de visitantes ao ano. Dados de 2005 registram, no início do século XXI, a criação de cerca de um novo jardim botânico a cada semana, em algum lugar do mundo, com recente crescimento significativo da China. (GALBRAITH; RAPLEY, 2005). No Brasil, a resolução de número 339/2003, do Conselho Nacional de Meio Ambiente (Conama) ${ }^{5}$, assinala que os jardins botânicos são áreas protegidas, constituídas no seu todo ou em parte, por coleções de plantas vivas "cientificamente reconhecidas, organizadas, documentadas e identificadas, com a finalidade de estudo, pesquisa e documentação do patrimônio florístico do País, acessível ao público, no todo ou em parte, servindo à educação, à cultura, ao lazer e à conservação do meio ambiente". ${ }^{3}$

\footnotetext{
3 http://www.portaloceania.com/nz-tourism-nationalparks-port.htm

4 The ten national botanical gardens - Free State, Hantam, Harold Porter, Karoo Desert, Kirstenbosch, Kwelera, Lowveld, KwaZulu-Natal, Pretoria and Walter Sisulu National Botanical Gardens - are located in seven of South Africa's nine provinces. [...] Combined, South Africa's national botanical gardens receive nearly 1.5 million visitors per annum, with Kirstenbosch, considered one of the world's 'Magnificent Seven' botanical gardens, receiving over 820,000 visitors per annum. Disponível em: http://www.sanbi.org/ gardens. Outras informações em: 〈http://www.africa-turismo.com/africa-do-sul/parques.htm〉. Ambos acessados em: 20 mar. 2015. 5 Conama é a sigla do Conselho Nacional do Meio Ambiente, órgão consultivo e deliberativo pertencente ao Ministério do Meio Ambiente. Disponível em: 〈http://www.mma.gov.br/port/conama/〉.

$6 \mathrm{http}: / /$ www.mma.gov.br/port/conama/legiabre.cfm?codlegi=377
} 
Cada jardim botânico, portanto, pode ser considerado e tratado como um museu vivo que, para além da materialidade de seus acervos, coloca-se como repleto de histórias e simbologias naturais e culturais. Possuem, assim, importante cunho educacional para as comunidades em que estejam inseridos, além de serem atrativos para atividades ao ar livre, onde moradores do seu entorno e turistas buscam conhecimentos, maior aproximação com a natureza e lazer qualificado. (GASTAL; FAGUNDES, 2015). Exemplo maior, no Brasil, é o Jardim Botânico do Rio de Janeiro. Outros desses espaços, entretanto, por carência de pessoal especializado, ou mesmo por falta de uma percepção para essa demanda por parte de seus gestores, relegam à espontaneidade a relação dos visitantes com a área. Bediaga (2007) ressalta que nem sempre é fácil aos visitantes perceber espontaneamente que, por trás da ordenação de plantas, existem estudos e pesquisa científica sendo realizados na área, pois estes tendem a se relacionar com o espaço botânico de maneira afetiva, inclusive com reminiscências pessoais. Políticas e práticas de interpretação patrimonial e de animação sociocultural, por exemplo, poderiam auxiliar em uma maior qualificação dos jardins botânicos na sua relação com visitantes, tanto em termos educacionais quanto de usufruto do lazer, desde que se conheçam melhor as demandas do público frequentador. (GASTAL; DA SILVA, 2015; MURTA; ALBANO, 2002; RYLAND, 2010).

Como já citado, há quatro jardins botânicos registrados no Rio Grande do Sul, de acordo com a Rede Brasileira de Jardins Botânicos, localizados em Porto Alegre, Caxias do Sul, Santa Maria e Lajeado. Se levarse em conta a extensão territorial do estado, chega-se à conclusão de que esse número seria inexpressivo. Em seu primeiro momento, a presente investigação priorizou Porto Alegre e Caxias de Sul, cidades-sede do projeto de pesquisa, devendo, em momento futuro, alcançar os demais, dentro do estado ${ }^{7}$.

O Jardim Botânico de Porto Alegre, localizado em bairro homônimo, possui uma área de 39 ha. A intenção de criar um botânico na cidade reporta a 1883, então com o objetivo de aproveitar científica e socialmente a várzea localizada no bairro Petrópolis. Todavia, somente em 1957 houve o início do plantio de espécies no local, sendo aberto ao público em 1958, com exposição de coleções de palmeiras, coníferas, cactáceas, agaváceas e liliáceas. Na década de 1970, o Jardim Botânico passa a integrar a Fundação Zoobotânica do Rio Grande do Sul. A partir de 1974, foram criadas coleções botânicas de espécies arbóreas [arboreto] organizadas por formações florestais, famílias botânicas e grupos temáticos. Hoje, trata-se de um dos cinco maiores jardins botânicos entre os 36 localizados no Brasil ${ }^{8}$, em termos de diversidade de coleções de plantas, qualificação estrutural e quadro técnico e operacional'. Localizado em uma das regiões de maior concentração populacional do estado, o Jardim Botânico de Porto Alegre visa à conservação integrada da flora nativa e dos ecossistemas regionais. Além disso, de acordo com o seu Plano Diretor (2004), tem como missão não ser apenas um parque de lazer, mas um espaço educativo, de pesquisa e conservação, além de desenvolver programa de educação ambiental e de uso público da área. Um conjunto de diretrizes busca conscientizar estudantes e visitantes sobre a importância da conservação da biodiversidade e dos ecossistemas locais. Destaca-se que dos 67.462 visitantes que o parque recebeu em 2015, 16.336 eram estudantes.

O Jardim Botânico de Caxias do Sul, criado em 1992, está localizado junto à represa São Paulo, na Bacia Hidrográfica do Arroio Dal Bó, na cidade de Caxias do Sul. É mantido pela Prefeitura Municipal, por meio de sua Secretaria Municipal do Meio Ambiente e do Serviço Autônomo Municipal de Água e Esgoto, em associação com a Universidade de Caxias do Sul. Cada entidade é responsável por determinadas atividades

7 Uma extensão da pesquisa envolve o Jardim Botânico da Universidade de Coimbra, Portugal. (GASTAL; PALMA, 2016).

8 www.rbjb.org.br.

9 http://www.fzb.rs.gov.br/jardimbotanico/ 
relacionadas à área, devendo disponibilizar recursos materiais, financeiros e humanos para funcionamento e manutenção do espaço e das pesquisas ali realizadas. A exemplo de outras áreas brasileiras similares, sua proposta original envolvia a criação de uma área de preservação e recuperação de espaços verdes urbanos e de bacias hidrográficas. A mesma proposta diz que deveria desenvolver funções científicas e educacionais e contribuir com um legado de biodiversidade às gerações atuais e futuras da comunidade local e regional. Quase metade da sua área é constituída por vegetação nativa, isto é, matas com Araucaria angustifolia, também conhecida por Floresta Ombrófila Mista, que no Sul do Brasil ocupa o chamado Planalto das Araucárias. Desde 2006, o Jardim Botânico de Caxias do Sul atua com o programa internacional Investing in Nature. Esse programa tem a parceria do BGCI, com o Instituto de Pesquisas do Jardim Botânico do Rio de Janeiro e com a Rede Brasileira de Jardins Botânicos. O projeto Salvando os Cactos, inicialmente com os gêneros Parodia e Frailea, originou a sua coleção de Cactaceae (WASSUN, 2009).

\section{BOTÂNICOS DE PORTO ALEGRE E CAXIAS DO SUL: PERFIL DO VISITANTE}

A pesquisa aplicada em Porto Alegre, em $2012^{10}$, teve por objetivo atualizar dados de investigação realizada em 2006, que avaliou o perfil sociocultural e percepção do frequentador sobre Jardim Botânico, assim como alimentar com dados preliminares a pesquisa "Educação Patrimonial e a Prática Turística Qualificada: O Jardim Botânico de Porto Alegre”, encabeçada pela Universidade de Caxias do Sul e pela Universidade Federal do RS, e que conta com apoio do CNPq. Já em Caxias do Sul, tratou-se da primeira intervenção investigativa no âmbito do macroprojeto, mantendo o mesmo instrumento de pesquisa. A Tabela 1 sintetiza os principais resultados que são, a seguir, comentados.

Tabela 1 - O Perfil do frequentador dos Jardins Botânicos de Porto Alegre e Caxias do Sul, 2016, 2012 e 2015 (dados de destaque).

\begin{tabular}{|c|c|c|c|}
\hline & JBPOA 2006 & JBPOA 2012 & JBCS 2015 \\
\hline $\begin{array}{l}\text { GÊNERO } \\
\text { Feminino [masculino] }\end{array}$ & $60,6 \%[39,6 \%]$ & $54 \%$ [46\%] & $38 \%[62 \%]$ \\
\hline $\begin{array}{l}\text { FAIXA ETÁRIA } \\
21-30 \\
31-40 \\
41-51\end{array}$ & $\begin{array}{l}26 \% \\
13 \% \\
24,5 \%\end{array}$ & $\begin{array}{l}29 \% \\
34 \% \\
17 \%\end{array}$ & $\begin{array}{l}19 \% \\
54 \%\end{array}$ \\
\hline $\begin{array}{l}\text { ESCOLARIDADE } \\
\text { Superior } \\
\text { Médio [incompl.] } \\
\text { Fundamental }\end{array}$ & $\begin{array}{l}57.3 \% \\
42.6 \% \\
0 \%\end{array}$ & $\begin{array}{l}54 \% \\
24 \%[2 \%] \\
9 \%\end{array}$ & $\begin{array}{l}47 \% \\
24 \%[9 \%] \\
20 \%\end{array}$ \\
\hline $\begin{array}{l}\text { RENDIMENTOS } \\
+10 \text { SM } \\
10-7 \text { SM } \\
6-4 S M \\
3-1 S M \\
\text { Sem renda }\end{array}$ & $\begin{array}{l}8.1 \% \\
14.7 \% \\
72.1 \%\end{array}$ & $\begin{array}{l}24 \% \\
12 \% \\
24 \% \\
27 \% \\
7 \%\end{array}$ & $\begin{array}{l}4 \% \\
2 \% \\
25 \% \\
53 \% \\
16 \%\end{array}$ \\
\hline
\end{tabular}

10 "O frequentador do Jardim Botânico de Porto Alegre”, 2012, coordenado por Antônio Carlos Castrogiovanni e Susana Gastal, contou ainda com a participação dos então mestrandos Andrea Silveira Pessoa (UCS), Bruno Nunes Batista (UFRGS) e Paola Pereira (UFRGS). 


\begin{tabular}{|c|c|c|c|}
\hline & JBPOA 2006 & JBPOA 2012 & JBCS 2015 \\
\hline $\begin{array}{l}\text { OCUPAÇÃO } \\
\text { Setor privado } \\
\text { Setor público } \\
\text { Empregadores } \\
\text { Estudantes }\end{array}$ & $\begin{array}{l}40.9 \% \\
9.8 \% \\
8.1 \% \\
18 \%\end{array}$ & $\begin{array}{l}29 \% \\
24 \% \\
17 \% \\
24 \%\end{array}$ & $\begin{array}{l}48 \% \\
3 \% \\
8 \% \\
16 \%\end{array}$ \\
\hline $\begin{array}{l}\text { RESIDÊNCIA } \\
\text { Na cidade } \\
\text { Outra cidade } \\
\text { Outro estado } \\
\text { Outro país }\end{array}$ & $\begin{array}{l}86.6 \% \\
11 \% \\
\text { [1 sujeito] }\end{array}$ & $\begin{array}{l}71 \% \\
24 \% \\
5 \% \\
\text { [1 sujeito] }\end{array}$ & $\begin{array}{l}88 \% \\
9 \% \\
3 \% \\
0 \%\end{array}$ \\
\hline $\begin{array}{l}\text { FREQUÊNCIA } \\
1^{0} \text { - vez } \\
\text { Anual } \\
\text { Mensal }\end{array}$ & $\begin{array}{l}11.4 \% \\
40.9 \% \\
42.5 \%\end{array}$ & $\begin{array}{l}20 \% \\
40.9 \% \\
10 \%\end{array}$ & $\begin{array}{l}22 \% \\
11 \% \\
35 \%\end{array}$ \\
\hline
\end{tabular}

Fonte: Pesquisa empírica, dos autores.

Os resultados porto-alegrenses, por surgirem em momentos diferenciados, permitiram avaliar, também, tendências. A pesquisa de 2012 indica uma leve predominância das mulheres [54\%] no universo pesquisado, em especial nos domingos à tarde, reduzindo percentuais de 2006 [60,6\%], ou seja, indica como tendência o maior equilíbrio entre ambos os sexos. A faixa etária predominante foi a dos 21 aos 40 anos [63\%], mas que em 2006 significava 39\%, de modo geral, indicando um rejuvenescimento da frequência. Em termos de nível de escolaridade, houve uma maioria [54\%] dos sujeitos com curso superior completo ou em desenvolvimento, tendo o ensino médio completo alcançado $24 \%$ e o incompleto apenas 9\%. Em 2006, o índice para terceiro grau [57,3\%] e com ensino médio completo [42,6\%] alcançava 100\% da amostra. Como tendência, indica-se uma diversificação no que se refere ao nível de escolaridade dos visitantes, com a atração de um público com relativa menor escolaridade, em anos recentes. Em Caxias do Sul, os resultados apontam a predominância do sexo masculino [62\%], dado que pode estar associado à prática da pesca, que é autorizada na represa ali localizada, em especial durante a semana. Nos finais de semana alteram-se as atividades desenvolvidas na área, havendo, da mesma forma, alteração no perfil de frequentadores, que passa a incluir grupos familiares. Com relação à distribuição etária, predomina a faixa entre 21 e 42 anos [75\%], como em Porto Alegre. A incidência de pessoas com escolaridade superior e média [71\%], não fica muito distante do encontrado na capital.

Em termos de renda, em Porto Alegre a maioria [52\%] recebe até seis salários mínimos e 24\% mais de dez salários, havendo apenas $6 \%$ sem renda, neste número devendo ser considerada a grande presença de estudantes. Em 2006, a faixa de até seis salários [72,1\%] era maior e apenas 8,1\% declararam receber além de dez salários. A faixa intermediária, entre sete e dez salários se manteve estável: 12\% agora e 14,7\% na pesquisa anterior. Como tendência, observa-se avanço na renda, mesmo com a diversificação, a menor, da escolaridade. No que se refere à ocupação, predominam empregados do setor privado [29\%] e do setor público [24\%], em percentual equivale ao de estudantes [24\%], mas também há empregadores [17\%]. Em 2006 tinham-se empregados públicos e privados [50,7\%] como maioria, os empregadores [8,1\%] e estudantes [18\%] apresentando menor índice, na comparação com 2012. Significa dizer que reduziu o número de empregados e ampliou o de empregadores e de estudantes. Em Caxias do Sul, a pesquisa aponta $16 \%$ desempregados; entre os que trabalham, $48 \%$ são empregados e os demais $36 \%$ distribuídos entre empregador, funcionário público, aposentado do INSS e estudantes. No total, 53\% dos entrevistados afirmaram receber entre um e três salários mínimos [até $\mathrm{R} \$ 2.364,00$ mensais, quando da aplicação da pesquisa], ou seja, uma renda média menor do que a detectada em Porto Alegre. 
A frequência majoritária [71\%] em Porto Alegre é de moradores da cidade, embora sejam apenas $7 \%$ os residentes no próprio bairro. Mas, não se pode desconsiderar a origem em outras sete cidades do estado, a metade localizada na região metropolitana [cidades de Canoas, Esteio, Gravataí e Viamão]. A presença de turistas vindos de fora do estado e de visitantes estrangeiros foi discreta. A pesquisa de 2006 encontrou índice ainda maior de porto-alegrenses [86,6\%] e menor entre os de fora da cidade [11,4\%] e, da mesma maneira, de um único estrangeiro. Como tendência, observa-se o crescimento da abrangência geográfica do parque, talvez pelo aumento da renda, permitindo o deslocamento intermunicipal, a lazer, ou seja, o Jardim Botânico não se beneficia, ainda, dos fluxos turísticos externos à cidade. Em Caxias do Sul, os visitantes [88\%] procedem da própria cidade, um pequeno número [9\%] vindo de outras cidades do estado ou de outro estado [3\%]. Não houve registro de visitantes do exterior. Uma grande diversidade de bairros [42] foi indicada como local de residência, demonstrando que o Jardim Botânico é eleito como destino, independente da distância urbana a ser percorrida. No entanto, observa-se maior incidência de público procedente dos bairros Centro e Fátima, o primeiro com melhor oferta de transporte e, o segundo, localizado próximo ao Jardim Botânico.

Em termos de frequência das visitas, um número significativo [20\% em Porto Alegre e 22\% em Caxias do Sul] da amostra, visitava o local pela primeira vez. A maioria [34\%] declarou visitas anuais, mas um número também significativo [27\%] não soube precisar, declarando outras periodicidades, em Porto Alegre; em Caxias do Sul, 35\% declararam visitas mensais. Em ambos os locais, é pequeno o número de frequentadores rotineiros, semanais ou diários. Em 2006, os de primeira visita eram em número menor $[11,4 \%]$ e as visitas anuais se mantiveram aproximadas nas duas pesquisas, então com 40,9\%; entretanto, os visitantes frequentes (semanais e mensais) eram em maior número [42,5\%]. Como tendência, não parece haver a fidelização dos visitantes, mesmo daqueles que residam no próprio bairro. É importante acrescentar a este, o item informação sobre a área, em que a maioria dos entrevistados [71\%] da capital, declarou não receber informações sobre o Jardim Botânico, regularmente; para esse público, a fonte de informação declarada com maior ênfase foi "outro" (79\%), seguindo-se o jornal (29\%), a Internet (21\%) e a televisão (14\%). Esse item não foi avaliado em 2006.

A principal motivação para a visita a ambas as áreas é o lazer, seguida pela busca de um maior contato com a natureza. Educação, no sentido de aprendizagem, e interesse botânico não superaram os 10\% em Porto Alegre e ficaram em zero, em Caxias do Sul. Em relação a 2006, há maior diversificação, pois então, 90,1\% declararam o lazer como motivo da visita, sendo a busca por contato com a natureza menor [4,9\%], assim como o interesse educacional [1,6\%]. Também se observou a busca por um lazer ativo e qualificado. No domingo e no sábado, chamou atenção dos pesquisadores o grande número de pessoas fotografando, não raro com equipamentos sofisticados, ou mesmo a movimentação para locações de produções profissionais.

Questionados sobre atividades no usufruto de tempo livre, os resultados em Porto Alegre sugerem estar-se frente a um público diferenciado, que gosta de programas culturais, como cinema [12\%] e leitura [10\%], de atividades em parques [19\%] e caminhadas [14\%], e que assiste à televisão [19\%] ou jogos eletrônicos [19\%] no tempo de lazer. Mas a Internet (19\%) também aparece como atividade de lazer. Em Caxias do Sul, do total de entrevistados, 30\% afirmam "visitar parques" em seu tempo livre; "caminhar" aparece logo em seguida [25\%]. Houve referência ainda a "assistir à televisão" [11\%], "navegar na Internet" [9\%], "ler" [5\%], "ir ao shopping" [8\%] e ao "cinema" [2\%] ${ }^{11}$. Como resposta aberta para a opção descrita

11 Esse item permitia respostas múltiplas. 
como "outro" [10\%], foram citadas atividades, como "viajar", "sair com amigos", "praticar esportes", "meditação" e "passear em família".

Sobre a estrutura do local, em Porto Alegre, somados os que a consideram ótima [22\%], com os que a consideram boa [59\%], chega-se a 81\% de aprovação positiva. Mas, em 2006, o total de aprovação fora de $99,9 \%$, ou seja, embora a aprovação ainda seja significativa, a insatisfação cresceu, de praticamente zero para $17 \%$. Isso tanto pode significar um público mais crítico, como mostram outras pesquisas sobre o perfil da nova classe média brasileira - uma classe, ao que parece, presente no Jardim Botânico em 2012 - como, talvez, a deterioração das instalações do parque no período entre as duas enquetes. Entre os equipamentos a acrescentar, as sugestões foram diversificadas, mas se pode agrupá-las em pedidos por equipamentos [16\%], como praças infantis, melhor infraestrutura de placas de identificação das plantas e estufas [42\%] e presença de serviços de monitoria [27\%], mas também houve a solicitação por maior divulgação e atenção à segurança. Em Caxias do Sul, as respostas revelam claramente o descontentamento com os itens relacionados à prestação de serviços; sobre o atendimento, $65 \%$ dos participantes o avaliam como ruim. Já $68 \%$ apontam como ruim a inexistência de material explicativo, e 52\% relatam a segurança como ruim no local. A infraestrutura e a limpeza figuram como boas, com, respectivamente, $53 \%$ e $61 \%$ de aprovação.

A sinalização do Jardim Botânico de Porto Alegre foi avaliada como ótima [12\%] ou boa [59\%] pelos entrevistados. Mas, a insatisfação, classificando-a como regular [12\%] e ruim [17\%] coloca-se como significativa. Em 2006 prevaleciam o ótimo [42,6\%] e o bom [52,4\%], em um somatório que chegava aos $95 \%$. Significa dizer que se repete o colocado sobre a infraestrutura: ou estamos em presença de um público mais exigente, ou as condições da área pioraram, em termos de sinalização. No atendimento pelos funcionários também predominou o bom [54\%], seguido do regular [20\%], ficando o ótimo [17\%] em discreto terceiro lugar. A segurança alcançou entre ótimo e bom [80\%], mas o ótimo fica em módicos $12 \%$, o regular e o ruim somando outros $12 \%$. Em 2006, 99,9\% acusaram a segurança em ótimo ou bom. Significa dizer que houve uma queda na percepção de segurança, entre os 99,9\% bastante satisfeitos em 2006, e os $80 \%$ atuais. O mais atingido foi o ótimo, que de $62,2 \%$ baixou para $12 \%$, em parte alimentando o bom, que de $37,7 \%$ passou para $68 \%$, mas tendo que conviver, agora, com os $7 \%$ que declararam a segurança como regular e os $5 \%$ que a veem como ruim.

Na avaliação do paisagismo, o ótimo [59\%] e o bom [27\%] predominam em Porto Alegre, mas aparecem o regular [10\%] e o ruim [2\%]. Em 2006, ótimo e bom somavam 99,9\%. A tendência, portanto, também indica queda do ótimo de $80,3 \%$ para os 59\%, parte da diferença indo alimentar o bom, que de $19,6 \%$ passa para 27\%, mas também o regular e até o ruim. Em Caxias do Sul, a percepção sobre o paisagismo assinalou o ótimo [43\%], enquanto 36\% das pessoas ouvidas avaliam como regular a sinalização encontrada no Jardim Botânico. Quando questionados sobre algum evento realizado no Jardim de Porto Alegre, 94\% do público relatou desconhecer qualquer tipo de divulgação sobre tal. Sobre as preferências em relação à área, houve destaques para as palavras "Calma", "Natureza", "Paisagem”, "Lagos" e "Fauna”, predominando o que estamos denominando como valores intrínsecos (ver Quadro 2). Como espaço favorito, destaque para os "Lagos" e "banhados", "trajetos" (trilhas) e "gramados", ou seja, predominam os espaços físicos em Porto Alegre, talvez induzido pela formulação da pergunta.

Em Caxias do Sul, quando questionados sobre "espaço favorito", todos os entrevistados citaram, espontaneamente, itens físicos. Embora as respostas sejam bastante diversificadas, aparecem em primeiro lugar [35\%], as "áreas verdes" com a sua "vegetação", o "cactário", a "grama", as "trilhas" e a "araucária", 
símbolo do JBCS. A represa, que muitas pessoas chamam de "lago", também aparece na preferência do público [25\%]. As instalações citadas como "espaços de convivência", "deck" e "quiosques" também foram lembradas [18\%]. Outra instalação do JBCS referendada como principal atrativo é o Jardim de Linneus [17\%]. Houve os que afirmaram "não ter local preferido" [3\%] ou que deram como resposta "todos os locais" [2\%]. Porém, quando o foco da pergunta aberta foi sobre o que mais gostou durante a visitação tem-se, a exemplo de Porto Alegre, percepções objetivas e subjetivas [valores intrínsecos], divididas entre espaços físicos e instalações [59\%], atividades possíveis de serem praticadas na área [12\%] e ainda sentimentos ou sensações [28\%], como "calma", "tranquilidade", "divertimento" e "observação" da natureza. Entre as atividades citadas aparecem "passear nas trilhas", "pescar", "relaxar e sair da rotina”, "passear com animais", "respirar ar puro" e "fazer exercício ao ar livre”; 1\% não soube opinar.

Quadro 2 - Valores atribuídos ao Jardim Botânico de Porto Alegre, RS.

\begin{tabular}{|c|c|}
\hline \multicolumn{2}{|c|}{ O QUE MAIS GOSTOU } \\
\hline 2012 & 2006 \\
\hline \multicolumn{2}{|c|}{ VALORES SUBJETIVOS } \\
\hline $\begin{array}{l}\text { Calma/Tranquilidade } \\
\text { Saúde/Saudável } \\
\text { Acolhimento } \\
\text { Liberdade } \\
\text { Não estar em POA } \\
\text { Silêncio } \\
\text { Diversidade }\end{array}$ & Calma/Paz/Tranquilidade \\
\hline \multicolumn{2}{|c|}{ VALORES OBJETIVOS } \\
\hline \multicolumn{2}{|l|}{$\begin{array}{l}\text { Caminhar } \\
\text { Piquenique }\end{array}$} \\
\hline \multicolumn{2}{|c|}{ VALORES INTRÍNSECOS } \\
\hline $\begin{array}{l}\text { Plantas/Flora/Vegetação } \\
\text { Natureza } \\
\text { Paisagem } \\
\text { Sol } \\
\text { Ar puro } \\
\text { Fauna } \\
\text { Ambiente }\end{array}$ & $\begin{array}{l}\text { Contato com a natureza } \\
\text { Paisagem/cenário/vista } \\
\text { Biodiversidade } \\
\text { Ar puro } \\
\text { Animais } \\
\text { Cheiro de mato }\end{array}$ \\
\hline \multicolumn{2}{|c|}{ VALORES EDUCATIVOS } \\
\hline \multicolumn{2}{|l|}{$\begin{array}{l}\text { Explicação do guia } \\
\text { Sinalização }\end{array}$} \\
\hline \multicolumn{2}{|c|}{ ESPAÇOS FÍSICOS } \\
\hline $\begin{array}{l}\text { Museu } \\
\text { Orquidário } \\
\text { Trilhas } \\
\text { Lago } \\
\text { Anfiteatro }\end{array}$ & $\begin{array}{l}\text { Museu } \\
\text { Orquidário } \\
\text { Trilhas } \\
\text { Lago } \\
\text { Anfiteatro }\end{array}$ \\
\hline
\end{tabular}

Fonte: Os Autores 
Questionados sobre sua percepção em relação ao que seria um jardim botânico, as respostas registram em Porto Alegre, tanto em 2006 quanto em 2012, que o frequentador tem consciência do perfil científico e de pesquisa e preservação da área. Entre outras, os visitantes afirmaram em relação à área: "Onde tem todas as amostras vegetais; berçário e manutenção, banco de vegetais"; "resenha de biodiversidade"; "reunião de espécies de vegetação"; "coleção de plantas mais diversificadas"; "local de exposição e conservação de espécies diferentes"; "preservação da natureza, fauna, o que é preciso para as gerações vindouras"; e, nesses termos: "Um lugar para explorar". Já em Caxias do Sul, as respostas à mesma pergunta registram que o frequentador não tem consciência do perfil científico, de pesquisa e preservação da área, como registra o Quadro 2.

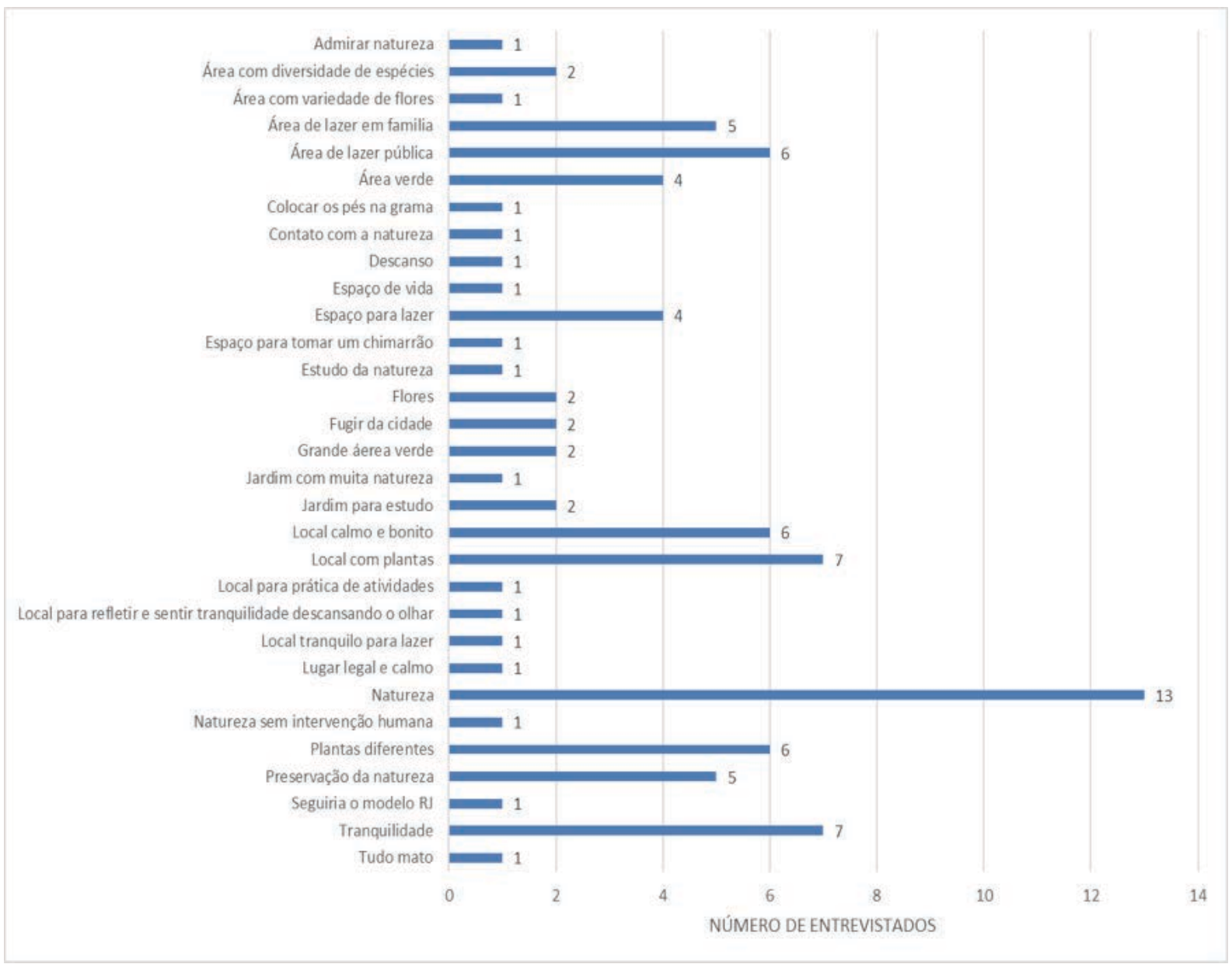

Figura 1 - Valores atribuídos ao Jardim Botânico de Caxias do Sul, RS.

Fonte: Os Autores

Há, muito forte, a ideia ou mesmo idealização dos dois Jardins Botânicos, expressas em afirmações como: "reserva natural no meio da cidade"; "um lugar reservado no meio da natureza"; "parque para contato com a natureza"; "um oásis no meio da cidade" que permitiria "uma fuga do cotidiano" e o "contato com a natureza". Esse oásis e local de fuga do cotidiano marcar-se-ia pela "tranquilidade", "ar puro", "centro de natureza, lugar de descanso", sendo um "lugar bonito, de beleza natural, com paz, tranquilidade", permitindo "relaxar" ou mesmo "relaxar, tomar chimarrão". Esse "parque legal" seria um "local para ver a natureza na região metropolitana" e um "espaço bonito, que possibilita contato com a natureza, difícil na cidade". Assim, coloca-se também como um "espaço de lazer e estudo", um "lugar lindo para fotografar", favorecendo "questão de saúde e contato com a natureza", mas sem esquecer que "além de local de lazer, 
é um centro de pesquisa", com a vantagem de ter "acesso gratuito, com custo baixo e boas instalações". Os entrevistados em Caxias do Sul, que demonstram a ausência de consciência sobre o perfil científico, de pesquisa e preservação da área, em suas respostas, relacionam o Jardim Botânico com as palavras "natureza" e "flores", descrevendo a área como um "local tranquilo" para "atividades de lazer". Apenas 18\% da amostra menciona a "diversidade de espécies" para "estudo" e "preservação da natureza". Esse "jardim de estudos" é apontado por essa minoria como um "local para refletir" e "descansar o olhar" da agitação da cidade.

\section{ENCAMINHAMENTOS}

Os resultados de pesquisas realizadas nos Jardins Botânicos de Porto Alegre e Caxias do Sul permitiram levantar não apenas resultados quantitativos sobre a presença de visitantes nas duas áreas, como abrir espaço de viés qualitativo que registrasse percepções mais amplas deles sobre as áreas em questão, como previsto nas pesquisas de audiência. Como proposto por Moussouri, ali estão visitantes [visitors] vindos de cidades próximas, mas também de outros estados; usuários [users], ou seja, visitantes constantes, ainda em pequeno número, e, presença predominando, a comunidade [community], pois o público no local envolve preferencialmente moradores de ambas as cidades, vindos de diversos bairros, para visitas ocasionais.

Constata-se, portanto, ser bastante importante o que o BGCI trata como "desenvolvimento de públicos" [audience development], buscando ampliar a frequência das visitas pela comunidade local, mas também investindo em ações que mobilizem outros segmentos sociais, econômicos e turísticos, pois os 67 mil visitantes registrados no Botânico de Porto Alegre ${ }^{12}$ ainda representariam números módicos de frequência, em termos de contribuir significativamente no que se refere à sustentação econômica da área ${ }^{13}$. Como mostrou a tendência a partir dos resultados comparados de Porto Alegre, tal ampliação já vem se dando, embora espontaneamente, pois a urbanização ao constranger os verdes no interior da cidade, ativa maior demanda por esses espaços. Em termos de turismo, a especialização das viagens leva à presença de públicos com demandas mais específicas e sofisticadas, fazendo crescer o turismo de nicho, mas também exigindo a qualificação da oferta turística, como registrado na bibliografia. As respostas podem vir de intervenções como as propostas pela interpretação patrimonial, ou mesmo pela animação sociocultural.

Entre as novas demandas nos jardins botânicos investigados, os resultados das pesquisas de audiência, em especial em Porto Alegre, indicam a expectativa pela experiência educativa que, embora ainda pequena, cresceu, significativamente em relação à pesquisa anterior, de 2006. Em decorrência, coloca-se o desafio de como construir o diálogo entre os jardins botânicos e seus públicos, no sentido de preparar as gerações contemporâneas não só para conviver com espaços verdes especializados na sua vocação para acervo e pesquisa de espécies, mas também que este aprendizado encaminhe ao como (con)viver em sociedade, em harmonia com o meio ambiente, o que sempre foi um dos grandes desafios de diferentes sociedades, em diferentes momentos históricos, e que agora se coloca também ao turismo.

120 Jardim Botânico de Caxias, por ter entrada franca e liberada, não apresenta registro do número de visitantes no local. Em Porto Alegre há ingresso pago para pessoas e carros.

13 Movimentos do Governo Estadual, em 2015 e até o momento, ameaçaram a privatização da área, no que contou com forte oposição da comunidade, em especial de grupos ambientalistas e acadêmicos. 
Na contemporaneidade, ante as questões colocadas pela economia e pela cultura da globalização, o desafio pode ser ainda maior. Se dos jardins botânicos o público frequentador espera o desfrute de momentos de calma e tranquilidade junto à natureza, além de uma experiência educativa, teóricos como Baptista (2008), associados à Pedagogia Social, defendem que tal aprendizado pode e deve estar associado a práticas de uma cidadania social, como forma de enfrentar a fragmentação, incertezas e vulnerabilidades, mas, muito especialmente, a aceleração dos fluxos, no momento atual; eles defendem a preparação dos sujeitos que farão com que o século XXI transborde a escola e abranja outros espaços e experiências da sociedade, incluindo aí as viagens e espaços de convivência, social e ecológica, onde o turista possa usufruir / exercitar tais possibilidades. Essa perspectiva alimentou a pesquisa, que investiga a possibilidade de que jardins botânicos sejam um desses espaços, para além de suas funções precípuas, quais sejam, a científica, a educacional, a social, a estética, a histórica, a ecológica e a turística, entre outras que poderiam ser listadas; que eles venham a ser um espaço de construção da cidadania, não só local, mas planetária, no sentido proposto por Morin (2003).

Batista e Castrogiovanni (2014) indicam ser necessário buscar caminhos de intervenção nos olhares dos visitantes, sejam eles o turista cidadão ou turista tradicional, que, por meio do impacto do estranhamento, estabelecem uma relação dialógica e transdisciplinar com tais áreas. Um olhar que possibilite compreender a produção histórica e a existência desse lugar na sua individualidade e no seu caráter de imagem polissêmica. O Jardim Botânico pode facilitar a educação do olhar atento e autoral e, em decorrência, mais cidadão, sobre o meio ambiente. Descrição e explicação são inseparáveis.

Por essa razão, os projetos por nós desenvolvidos, que deram sequência à pesquisa de audiência aqui relatada, concebem os Jardins Botânicos como um laboratório vivo, espaço turístico-pedagógico, onde se busque o significado das suas formas, de sua organização, dos seus componentes nativos e exóticos, como um caminho para a valorização dessa área, que vá além do lazer, repita-se, para turistas externos ou cidadãos turistas. Em ambos os públicos, a vivência com esses locais qualifica os cotidianos em viagem ou no local. Retomando Franklin e Crang (2001), a cultura do cotidiano - ou seja, o dia a dia de muitas camadas da sociedade $\neg$ - hoje é semantizada pela experiência turística, que condiciona o modo como percebemos o mundo a nossa volta, não só quando em viagem para locais fora daqueles de residência.

Em outras palavras, a busca pelos jardins, nas sociedades contemporâneas, deixa de se dar como excepcionalidade e passa a integrar a vida cotidiana, embora nesses termos possa avançar tanto em Porto Alegre como em Caxias do Sul, supondo o cotidiano como aberto ao estranhamento, que conduz à aquisição de novos conhecimentos. No turismo de nicho há a reconfiguração da figura do turista, agora não mais demarcado pelas distâncias físicas que percorre, mas em uma tipologia que pode envolver experiências diferenciadas também nos cotidianos. Estranhamento e novos olhares consolidarão os jardins como atrativos turísticos urbanos, permitindo pensar a atratividade das cidades. Enfim, os resultados aqui apresentados instigam a pensar o turismo em outras opções, formatações e locais, que não aqueles associados às expressões massivas e tradicionais da atividade. 


\section{REFERÊNCIAS}

BAPTISTA, I. Hospitalidade e eleição intersubjectiva: sobre o espírito que guarda os lugares. Revista Hospitalidade, v. 5, n. 2, 2008, p. 5-20.

BATISTA, B. N.; CASTROGIOVANNI, A. C. A (re)descoberta da natureza: é possível ensinar geografia no Jardim Botânico. In: CASTROGIOVANNI, A. C. et al. (Org.). Aprender a ensinar Geografia: a vivência como metodologia. Porto Alegre, Evangraf, 2014.

BATISTA, B. N. Geografia no Jardim Botânico de Porto Alegre: a aventura do conhecimento. Dissertação (Mestrado em Geografia) - Universidade Federal do Rio Grande do Sul. Programa de Pós-Graduação em Geografia, Universidade Federal do RS, 2014.

BEDIAGA, B. Conciliar o útil ao agradável e fazer ciência: Jardim Botânico do Rio de Janeiro - 1808 a 1860. História, Ciência e Saúde, v.14, n. 4, 2007.

BOTANIC GARDEN CONSERVATION INTERNATIONAL (BGCI), 2010. Disponivel em: <http://www.bgci. org). Acesso em: 20 set. 2015.

BRASIL. Ministério do Meio Ambiente. Conama. Resolução 339. Brasília, 2003. Disponível em: 〈http:// www.mma.gov.br/port/conama/legiabre.cfm?codlegi=377>. Acesso em: 27 set. 2015.

BRUM, P.; SANTIAGO, J. Os Jardins Históricos de Macau: proposta de um itinerário turístico. Dissertação (Mestrado em Arquitectura Paisagista) - Instituto Técnico de Lisboa, 2011.

CAMARGO, H. L. Uma pré-história do turismo no Brasil. Recreações aristocráticas e lazeres burguês (1808 - 1850). São Paulo: Aleph, 2007.

CAMPOS, L. J. O Museu é o Mundo: intervenção na cidade e estranhamento do cotidiano nos fluxos urbanos. Rosa dos Ventos, Turismo e Hospitalidade, v. 4, n. 4, 2012, p. 599-608.

CAVALHEIRO, F.; ROCHA, Y. T. Aspectos históricos do Jardim Botânico de São Paulo. Revista Brasileira de Botânica, v. 24, n. 4, (suplemento), p. 577-586.

DE ANGELIS, B. L. D.; DE ANGELIS NETO, G. Paisagem, turismo e planejamento urbano. Acta Scientiarum, v. 20, n. 4, 1998, p. 537-543.

FRANKLIN, A.; CRANG, M. The trouble with tourism and travel theory. Tourist Studies, v. 1, n. 1, 2001, p. 5-22.

GALBRAITH, D.; RAPLEY, W. Research at Canadian zoos and botanical gardens. Museum Management and Curatorship, v. 20, 2005, p. 313-331.

GALLI, P. Cidades e desenvolvimento de destinos turísticos secundários: uma abordagem com foco no sistema de transporte aquaviário. Caderno Virtual de Turismo. Rio de Janeiro, v.15, n. 3, 2015, p. 362-377.

GASTAL, S.; DA SILVA, A. F. Jardins e Jardim Histórico: espaço de memória e possibilidades para o turismo. Revista Ibero-Americana de Turismo, número especial, out. 2015, p. 63-85,

GASTAL, S.; MOESCH, M. Turismo, políticas públicas e cidadania. São Paulo: Aleph, 2007.

GASTAL, S.; FAGUNDES, A. Lazer, tempo e espaço: o Jardim Botânico de Porto Alegre, RS. In: XII SEMINÁRIO ANPTUR, 2015, Natal, RN. Anais... Caxias do Sul, RS: Educs, 2015, p. 1-15. Disponível em: 〈http://www.anptur.org.br/anptur/anais/v.11/DCL4_pdf/27.pdf〉. 
GASTAL, S.; PALMA, V. R. Historic gardens and patrimonialization by Unesco: the Botanic Garden of Coimbra, Portugal. In: HENRIQUES, C.; MOREIRA, M. C.; CESAR, P. A. B. (Org.). Tourism and History, World Heritage - Case Studies of Ibero-American Space. Braga, Portugal: Interdisciplinary Centre of Social Sciences / University of Minho, 2016, p. 123-144.

HORTA, M. L.; GRUNBERG, E.; MONTEIRO, A. Q. Guia básico de educação patrimonial. Brasília: Instituto do Patrimônio Histórico e Artístico Nacional, Museu Imperial, 1999.

INSTITUTO BRASILEIRO DE GEOGRAFIA E ESTATíSTICA (IBGE). Município de Porto Alegre. Disponível em: 〈http://cod.ibge.gov.br/6Lo〉. Acesso em: 20 mar. 2016.

JAMESON, F. Cultura do dinheiro. Petrópolis: Vozes, 2001.

MASCARENHAS, G. Cidade mercadoria, cidade-vitrine, cidade turística: a espetacularização do urbano nos megaeventos esportivos. Caderno Virtual de Turismo. Edição especial: Hospitalidade e políticas públicas em turismo, v. 14, supl.1, 2014, p. 52-65.

MOLINA, S. Pós-turismo. México: Edição do Autor, 2003.

MORIN, E. Cabeça bem feita. Rio de Janeiro: Bertrand Brasil, 2003.

MOUSSOURI, T. Good connections making audience research a collaborative process. BGCI-Roots, v. 10, n. 2, 2013, p. 6-9. Disponível em: 〈http://www.bgci.org/files/Worldwide/Education/Roots_PDFs/ Roots\%2010:2\%20.pdf>

MURTA, S. M.; ALBANO, C. (Org.). Interpretar o patrimônio: um exercício do olhar. Belo Horizonte: UFMG, 2002.

PALMA, V. R.; GASTAL, S. A. Turismo, interpretação patrimonial e jardins botânicos: o frequentador do Jardim Botânico de Caxias do Sul. Revista Brasileira de Iniciação Científica, v. 3, 2016, p. 90-110.

ROCHA, Y. T.; CAVALHEIRO, F. Aspectos históricos do Jardim Botânico de São Paulo. Revista Brasileira de Botânica, v. 24, n. 4, 2001, p. 577-586.

RYLAND, P. Who Goes There? Association for Heritage Interpretation Journal, v. 12, n. 2, 2010.

SILVA, S.; CARVALHO, P. Os jardins históricos: da dimensão patrimonial ao seu potencial turístico. Turismo \& Sociedade, v. 6, n. 3, 2013, p. 605-625.

SILVA, S. M. P. A dimensão patrimonial e o potencial turístico dos jardins históricos: o caso de Portugal. Biblio 3w: revista bibliográfica de geografía y ciencias sociales, v. 18, 2013.

URRY, J. O olhar do turista. São Paulo: Sesc/Studio Nobel, 1996.

VAN VALKENHOEF, L. Audience participation using visitor surveys to drive innovation. BGCI-Roots, v. 10, n. 2, 2013, p. 18-21.

WANG, X.; HE, H. Binocular vision puts new audiences in the frame. BGCl-Roots, v. 10, n. 2, 2013, p. 26-29.

WASSUN, R. XVIII REUNIÃO DE JARDINS BOTÂNICOS. Anais... Salvador, 2009, p. 60-62.

WHITE, R. A. Recepção: a abordagem dos estudos culturais. Comunicação \& Educação, v. 12, 1998, p. 57-76,

WILLISON, J. First word: our audience keeps us real and relevant. BGCI-Roots, v. 10, n. 2, 2013, p. 2-5. 